\title{
Advances in the Treatment of Anxiety: Targeting Glutamate
}

\author{
Asher B. Simon and Jack M. Gorman \\ Mount Sinai School of Medicine, Department of Psychiatry, Laboratory of Clinical Psychobiology, New York, New York 10029
}

\begin{abstract}
Our current psychopharmacological treatments for anxiety disorders evince a number of shortcomings, including troublesome side effects and lack of primary effects. Whereas many new drugs have been developed in the past few decades, most are based on outmoded theories of the pathogenesis of these disorders (i.e., monoamine hypotheses), thus frustrating our ability to create more specific and effective interventions. Recently, however, the neurobiological literature has shown a convergence of findings focusing on the glutamatergic system in anxiety disorders, and the growth of pharmacological tools
\end{abstract}

targeting these receptors has led to the development of novel treatments having anxiolytic effects in humans and animals alike. Additionally, as this system is showing promise as a final common pathway in the pathogenesis of anxiety disorders, we may be able to employ glutamate-specific neuroimaging techniques (e.g., N-acetyl-aspartate, GLX) to both guide treatment decisions and present reliable objective biomarkers for treatment efficacy. Key Words: Glutamate, anxiety, stress, psychopharmacology, treatment, NMDA antagonist

\section{INTRODUCTION}

It is clear that anxiety disorders exist as the locus of much suffering. However, anxiety in and of itself is frequently adaptive and serves primarily to protect the organism from both present and future harm. In normal human subjects, fear and anxiety are produced in response to a variety of exteroceptive, interoceptive, and cognitive inputs and allow the individual to assess his or her environment and make appropriate behavioral adjustments. In life-threatening situations, the brain's anxiety network allows for this activation below the level of conscious awareness such that responses can occur as quickly as possible. This hard wiring has been highly conserved throughout evolution, ${ }^{1}$ thus making it possible to study, at least in part, human anxiety through multiple animal models, from rodents to primates.

The neurobiology of anxiety has been well delineated and partially localized to one of the phylogenetically oldest areas of the brain. When a threatening stimulus is detected, the information is relayed through the thalamus and then takes one of two paths, the so-called "low-road" or "high-road." 2 The low-road transmits the information directly to the amygdala that compares it with stored

Address correspondence and reprint requests to Asher B. Simon, M.D., Mount Sinai School of Medicine, Department of Psychiatry, One Gustave L. Levy Place, Box 1230, New York, NY 10029. E-mail: asher.simon@mssm.edu. threatening or fearful material, conducting a preliminary and crude threat assessment. Along the high-road, information travels through the secondary and heteromodal sensory association cortices reaching the level of consciousness before it eventually reaches the amygdala. The faster monosynaptic low-road serves to constantly monitor the internal and external environments for threatening signals and modulates the moment-to-moment level of vigilance of the organism. Normally, this cue-driven amygdalar activity is reigned in by the hippocampus and areas of the prefrontal cortex, all of which help the organism determine whether the stimuli continue to be threatening in a given context (i.e., one can remain seated while in a doctor's office as a stranger approaches with a needle). However, in the presence of threatening stimuli, the amygdala is able to overcome this baseline tonic inhibition and modulate cortical processing at an early and initial stage, thus preceding and influencing the later corticoamygdalar inhibitory projections. In effect, when sufficiently activated, the amygdala tells the cortex what to look for, directing and focusing attention toward what it believes are dangerous stimuli. In anxiety disorders, these stimuli are not truly dangerous to the individual but are perceived as such, mediated by a generally overactive or hypertrophied amygdala and a weakened inhibition from the hippocampus and prefrontal cortex. Different anxiety disorders are marked by their own idiosyncratic fears and types of memories 
stored in the amygdala; a crude approximation of our current thinking is the following: post-traumatic stress disorder (traumatic cues), panic disorder (bodily sensations), social phobia (interpersonal ridicule/embarrassment), and specific phobias (specific items). Note that all are marked by a misapplication of threat to seemingly benign situations, mediated by concrete and rigid amygdalar control over more flexible cortical systems. It is this learning and hyperresponsivess that is the focus of much of the experimental therapeutics applied to the field of anxiety disorders. [We should note that although it seems likely that the idiosyncratic fearful situations in generalized anxiety disorder (GAD) and obsessive-compulsive disorder (OCD) are also stored in amygdalar representations, both of these disorders evince an increase in prefrontal cortical functioning - the opposite of the above disorders. ${ }^{3,4}$ In fact, there is some discussion as to whether OCD should be removed from the anxiety disorders category due to its divergent neurobiology. ${ }^{5}$ Whereas the neurobiology of GAD is just beginning to be studied in greater detail, it is possible that it represents a pathological cortical compensatory response to an overactive fear/anxiety locus].

\section{PSYCHOPHARMACOLOGICAL TREATMENT OF ANXIETY, AND ITS SHORTCOMINGS}

It was long thought that anxiety disorders were the result of an overexcited brain unable to effectively discharge pent-up energy. ${ }^{6}$ Thus, the earliest modern psychopharmacological treatment of such anxiety was the application of sedating medications, namely barbiturates and benzodiazepines, which have their effects through GABA receptors. Although highly effective, these medications have significant adverse effects that limit their potential (e.g., dependence, sedation, ataxia, memory impairments, and weakness). This fueled the search for novel antianxiety agents, which took a step forward with the development of antidepressants (1960s) and more selective serotonin modulators (selective serotonin reuptake inhibitors [SSRIs], 1980s), which were shown to be as effective for many anxiety disorders as they were for depression. As such, more patients with these conditions can now be safely and successfully treated than before, and there is evidence that suicide rates in many countries are beginning to drop because of pharmacotherapy for depression and anxiety disorders. ${ }^{7-9}$ (However, we should note that a recent study by Kessler et al. ${ }^{10}$ found no significant decrease in suicidal thoughts, plans, gestures, or attempts in the U.S. during the 1990s.)

Nevertheless, the field recognizes many shortcomings with respect to the pharmacological treatment of anxiety that still limit our success in treating patients. ${ }^{11,12}$ These can be summarized as follows: 1) Efficacy: In clinical trials, response rates to antidepressant medications for major depression and specific anxiety disorders are usually only about $60 \% .{ }^{13-16}$ Despite statistical separation from placebo, this therapy does not work for a substantial proportion of the clinical population. ${ }^{17}$ 2) Adequacy of response: Even among responders to antidepressant medications, a significant amount of residual symptomatology and functional impairment frequently persists, ${ }^{18}$ often resulting in the coprescription of more medications, making polypharmacy the rule rather than the exception. 3) Tolerability: Although newer antidepressants are safer than older drugs in terms of lethality in overdose, ${ }^{19}$ they nevertheless impose substantial adverse side effects, including sexual dysfunction ${ }^{20}$ and weight gain, ${ }^{21}$ that lead to premature termination of treatment. 4) Objective markers of treatment success: The judgment as to whether a treatment has worked for anxiety is generally based solely on subjective assessments (from the doctor and the patient). Although slightly more objective markers are available for a few subtypes of anxiety disorders in terms of ability to tolerate previously phobic situations (e.g., ability to approach a previously avoided object/ situation after systematic desensitization and/or exposure), we as yet have no reliable objective biomarkers that assist patients and clinicians in judging the adequacy of pharmacological treatments. 5) Rationally based treatment: Our current first line medications for anxiety and depression are mostly reiterations of treatments discovered by serendipity (i.e., multiple classes of medications targeting the brain monoamine systems). ${ }^{22,23}$ Almost none was developed based on molecular or preclinical neuroscience. Hence, we cannot assert that any of our current treatments actually target a known pathophysiology related to anxiety, frustrating our ability to make progress in developing more effective medications. ${ }^{12,17,24,25}$

We conclude, therefore, that the field of developing pharmacological treatments for mood and anxiety disorders is currently mired in a reiterative process that persists in coming up with variations on the monoamine reuptake inhibitor strategy - a gross intervention discovered by chance. It is unlikely that this approach will presage more effective or better tolerated medications for depressive and anxiety disorders. ${ }^{12,26}$

We should note here that the frequent use of the conjunction depressive and anxiety disorders is intentional and is based not only on the overwhelming comorbidity between the two conditions, but also on the fact that our first-line medications for anxiety disorders are in fact antidepressants. Most clinical studies of one succeed in excluding patients with the other from their samples, but because the same treatments may be effective for each, this is arguably artificial and an application of a rule that does not always play out in clinical reality. Importantly, we do not know many of the details about the frequently comorbid, intimate, and possibly related nature of de- 
pression and anxiety, either phenomenologically or psychobiologically. ${ }^{27-29}$

\section{NEW DEVELOPMENTS IN THE PHARMACOLOGY OF ANXIETY}

Technology has progressed such that we can begin to use increasingly intricate preclinical and clinical methods to advance new strategies for the treatment of mood and anxiety disorders. Many new theories and compounds have been proposed, including those based on 5- $\mathrm{HT}_{1 \mathrm{~A}}$ agonists ${ }^{10}$ and other specific serotonin-based compounds, ${ }^{30,31}$ NK-1 antagonists and other Substance P-related species, ${ }^{28}$ neuropeptides (NPY, NPS), ${ }^{29,32}$ more specific $\mathrm{GABA}_{\mathrm{A}}$ agonists, ${ }^{33,34} \mathrm{CRF}$ antagonists, ${ }^{35,36}$ glutamate modulators, and $\beta$-blockers, ${ }^{37,38}$ among others.

The primary approach we will present here is based on the hypothesis that one unifying pathophysiological feature of several anxiety conditions is excessive excitatory amino acid neurotransmission in response to stress. Based on preclinical and clinical evidence from our group and others, we will discuss the modification of glutamatergic neurotransmission in the CNS as an approach to finding more effective and better tolerated treatments. ${ }^{26,39-41}$

\section{GLUTAMATE AND STRESS}

There is now abundant evidence that 1) exaggerated response to stress due to constitutive and genetic factors $^{27,42,43}$ and/or 2) exposure to chronic levels of stress, are key components in the vulnerability to develop mood and anxiety disorders. ${ }^{44,45}$ Preclinical studies have shown that excitatory neurotransmission, mediated in part by elements of the glutamatergic neurotransmission system, is enhanced by stress. ${ }^{46-50}$ The effects of glutamatergic neurotransmission are multiple and widespread in the CNS, and it has been reported that up to $40 \%$ of all synapses have a glutamatergic element. ${ }^{51}$ Glutamate receptors are split into several types, most broadly demarcated as ionotropic and metabotropic. ${ }^{52}$ The former include the NMDA, AMPA, and kainate receptors. The metabotropic receptors have a modulatory role and will be discussed later. The NMDA receptor mediates fast excitatory transmission and is frequently colocalized with either AMPA or kainate receptors, which are thought to amplify the glutamatergic signal. Each of these complexes has its highest density in limbic and cortical regions; activation of the ionotropic receptors can result in effects on cognition, learning, and memory, inhibition of hippocampal neurogenesis and other effects on neuroplasticity, pain perception, and neuroendocrine regulation. ${ }^{52-54}$ However, their dysregulated and excessive activation leads to excitotoxicity with increased cal- cium ion entry and death of neurons. ${ }^{24}$ Although complex, the effects of glutamatergic neurotransmission can be simplified as biphasic: controlled glutamatergic neurotransmission is critical for ongoing higher order mental processes, whereas excessive neurotransmission leads to impairment of normal neuronal processes and even cell death. ${ }^{55,56}$ For many reasons, some of which are detailed below, it is possible that medications that modulate glutamatergic neurotransmission may be effective in treating mood and anxiety disorders. ${ }^{26,39,40,52,57}$

\section{GLUTAMATERGIC NEUROTRANSMISSION IN FEAR AND THE AMYGDALA}

It is now well known that activation of neuronal processes within the lateral nucleus of the amygdala (LA) is essential for the acquisition, manifestation, and longterm memory of conditioned fear in all mammalian species studied (see reviews by Davis and Whalen ${ }^{58}$ and LeDoux $\left.{ }^{59}\right) .{ }^{60}$ The circuits, cellular responses, and molecular events that are necessary to sustain conditioned fear have been worked out in detail and include the activation of glutamatergic pathways that synapse on LA neurons, which then project to the central nucleus producing behavioral and autonomic responses. ${ }^{61,62}$ (However, we should note here that although the importance of the amygdala for the acquisition and consolidation of conditioned fear memory is unequivocal, many other parts of the extended amygdala, particularly the bed nucleus of the stria terminalis, have been implicated in more chronic forms of fear and avoidance.) The mode by which classical fear conditioning is manifest in the amygdala is the following. ${ }^{52,63}$ A neutral stimulus leads to a certain amount of amygdalar glutamate release that binds to NMDA and AMPA/kainate receptors, but this weak activation and depolarization are not strong enough to dislodge the $\mathrm{Mg}^{2+}$ that partially blocks the NMDA channel. A strong and aversive stimulus, on the other hand, produces sufficient depolarization to allow full permeability of the NMDA receptor and ion channel. When administered together, the previously neutral stimulus begins to take on the neurochemical signature of the aversive stimulus. What seems important for our considerations is the dynamic balance between inhibitory (GABAergic) and excitatory (glutamatergic) transmission. ${ }^{52,64}$

Many studies using functional neuroimaging have shown that acute fear in normal humans is reliably accompanied by activation of the amygdala ${ }^{65}$ and that exaggerated amygdala activity occurs in patients with depression, ${ }^{66}$ panic disorder, ${ }^{67}$ social anxiety disorder, ${ }^{68}$ posttraumatic stress disorder, ${ }^{69}$ and trait worry in individuals without a psychiatric illness. ${ }^{43}$ Along these lines, there is evidence that NMDA receptor antagonists applied to the LA abolish, in a reliable manner, the acqui- 
sition and extinction of conditioned fear in rodent models of anxiety. ${ }^{70-74}$ Additionally, recent evidence has shown that NMDA partial agonists facilitate conditioned fear extinction in rodents and in humans with phobic disorders. ${ }^{75}$ This makes it possible that the same biological processes responsible for conditioned fear in experimental animals are also involved in fear responses in both normal humans and in those with pathological anxiety. Further evidence supporting this similarity in biological processes is found in our recent study, ${ }^{76}$ which showed that a standard SSRI, citalopram, when applied to a rodent model of fear conditioning, produces effects that are highly reminiscent of those observed when the drug is administered to patients with depression or anxiety disorders. That is, an acute dose of citalopram produces more fearful (i.e., freezing) behavior in fear conditioned rats, whereas chronic administration causes less fearful behavior when compared to vehicle.

\section{NMDA RECEPTOR SUBUNITS IN LTP AND LTD}

In that same study, ${ }^{76}$ we also found that chronic, but not acute, administration of citalopram induces downregulation of the NR2B subunit of the NMDA receptor. ${ }^{77}$ This raises the possibility that a mechanism of action of antidepressant drugs critical to reducing fear behavior may be by affecting the functional sensitivity of the glutamatergic neurotransmission system. ${ }^{78-81}$ Recent data ${ }^{82}$ suggesting that the NR2B subunit is important for hippocampal LTD (whereas the NR2A subunit is important for LTP) are of great interest and potential clinical relevance and deserve consideration in drug discovery efforts. However, we should note here that a recent paper ${ }^{83}$ found NR2B to be just as involved in LTP as NR2A and made a good case that the above NR2 subunit distinction between LTP and LTD is mistaken. More research is clearly needed.

This system is also largely affected by environmental stress. Recently, it was shown that rats that underwent restraint-tail-shock stress manifested an increase in hippocampal LTD via a mechanism by which stress activates glucocorticoid receptors, inhibiting the uptake of glutamate, leading to a spillover and temporal summation of glutamate at extrasynaptic NR2B-containing NMDA receptors, inducing hippocampal LTD. ${ }^{84}$ The authors of this study note that there is no clear mechanism by which stress impairs glutamate reuptake, but they describe previous work in their laboratory showing that stress may lead to a phosphorylation-induced inactivation of glutamate-aspartate transporters, thus allowing the extrasynaptic spillover of glutamate. Along these lines, it is interesting to note that the antibiotic ceftriaxone has recently been found to be a potent stimulator of increased GLT1 (glutamate transporter, also known as
EAAT2) transcription and expression, and it is currently being studied in many neurodegenerative diseases from stroke to amyotrophic lateral sclerosis. ${ }^{85}$ (see Maragakis and Rothstein ${ }^{86}$ for review of glutamate transporters). Additionally, a recent review ${ }^{87}$ described the possible utility of antagonizing the NR2B subunit of the NMDA receptor as a treatment for alcohol dependence, noting that in vivo and in vitro experiments found elevated NR2B expression after chronic ethanol exposure. The authors theorized that NR2B antagonists would clinically block the enhanced NMDA receptor activation that accompanies chronic ethanol exposure. It is also foreseeable that such treatments would be effective in ameliorating the affective instability and anxiety that so often accompanies not only chronic alcohol ingestion but also alcohol withdrawal.

Finally, two interesting things we can mention further about NR2B are:1) NR2B is more important than NR2A during brain development, and although this reverses as the brain matures, authors make important statements that NR2B subunits still abound in the mature brain ${ }^{88,89}$; and 2) LeDoux's model is concerned with NR2B because it is critical in the acquisition of fear conditioning, and they have found a selective blocker of NR2B receptors, ifenprodil, to be effective in blocking acquisition. ${ }^{73}$

\section{ANTIDEPRESSANT EFFECTS ON GLUTAMATERGIC NEUROTRANSMISSION}

Data suggest that chronic administration of antidepressant drugs (SSRIs, SNRIs, TCAs, and MAOIs) decreases glutamatergic activity in specific regions (including the PFC and hippocampus) $)^{90-92}$ and that acute administration of NMDA receptor antagonists have antianxiety and antidepressant properties in preclinical and clinical mod-

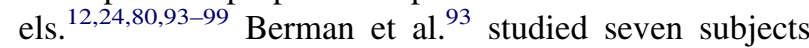
with major depression who, in a double-blind placebocontrolled manner, received intravenous ketamine or saline with active and sham treatments separated by at least 1 week. They noted a significant reduction in Hamilton Depression Rating Scale scores within $72 \mathrm{~h}$ after ketamine but not placebo, with results lasting for nearly 1 week. Although clearly ketamine is not viable as a chronic antidepressant or antianxiety medication given its significant cognitive and dissociative effects, we have theorized its use in a manner similar to electroconvulsive therapy (ECT). For example, the patient is given a ketamine-infusion treatment and concurrently started on an antidepressant; the infusion is repeated weekly for perhaps two to three total sessions, and by then, the standard antidepressant will have kicked in. This allows for the patient's receiving an immediate antidepressant response. Along these lines, it is noteworthy that Anand et al. ${ }^{100}$ showed that preadministration of lamotrigine to ketamine-receiving subjects both attenuated the latter's 
neuropsychiatric effects and increased its immediate mood-elevating effects. Thus, concurrent treatment with lamotrigine may ease the side effects of the ketamine infusion in the ECT analogy noted above. Lamotrigine functionally inhibits glutamate release and is currently used as an anticonvulsant as well as a treatment for bipolar depression. Another small clinical study has shown lamotrigine to be effective in certain PTSD symptoms (re-experiencing and avoidance/numbing). ${ }^{101}$ Similarly, topiramate, an AMPA/kainate blocker among other actions, was found in an open-label study to reduce re-experiencing symptoms in PTSD. ${ }^{102}$

\section{GLUTAMATE AND DENDRITIC REMODELING}

It is of crucial importance to the field to develop hypotheses that link theories about the pathophysiology of mood and anxiety disorders to drug discovery. As noted above, there is now ample evidence that stress and stress-induced glutamatergic neurotransmission are important factors in vulnerability to mood and anxiety disorders. Bruce McEwen (see reviews by McEwen ${ }^{47}$ and Sapolsky ${ }^{103}$ ) originally showed evidence of hippocampal dendritic remodeling in response to stress; notably, this was blocked by the atypical antidepressant drug tianeptine. ${ }^{104-106}$ Recently, John Morrison's group ${ }^{107}$ reported a similar finding that chronic restraint stress (an animal model of depression ${ }^{108}$ ) causes dendritic remodeling of pyramidal cells in the rodent prefrontal cortex. Specifically, there was a dramatic shortening of dendrites and loss of dendritic spines. Importantly, the cell bodies from these neurons remained intact. This shrinkage observed in these animal models has putative similarities to the hippocampal, subgenual, and prefrontal cortical volume losses observed in certain affective and anxiety disorders in humans as well as their reversal after treatment with effective antidepressants or ECT. ${ }^{109-113}$ In the case of chronic stress, high cortisol levels in conjunction with glutamate excess could contribute to this cellular injury. ${ }^{103}$ In fact, studies have shown that glutamate infusions into cultured rat amygdala neurons stimulate CRF release in a concentration-dependent manner ${ }^{114}$; of note, this stimulation was blocked by an NMDA antagonist. Thus, enhanced glutamate release could contribute to glucocorticoid-induced neurotoxicity, ${ }^{49,50}$ the reversal of which could be important in psychopharmacological treatment. See reviews by Manji et al. ${ }^{17}$ and Duman and Carlson et al. ${ }^{115,116}$

This shrinkage appears to disrupt the functionality of the neurons and their signaling, but it may in fact be compensatory or adaptive. ${ }^{117}$ In postsynaptic neurons in the CNS, NMDA and AMPA receptors are actively shuttled between the membrane and cytoplasm by a clathrindependent mechanism ${ }^{118}$; of note, in mature cultures,
NR2B undergoes more robust endocytosis than NR2A, consistent with previous studies showing NR2A to be more highly expressed at stable synaptic sites. ${ }^{119}$ Thus, one mechanism for terminating excessive glutamatergic neurotransmission and the sustained activation of NMDA receptors is the internalization of these receptors. ${ }^{118}$ Interestingly, NMDA receptors are functionally downregulated at synapses as a result of fear learning. ${ }^{117}$ We hypothesize that, during acute stress, internalization of glutamatergic receptors occurs and functions as an adaptive method of reducing the excitotoxic effects of glutamate on postsynaptic neurons, and during more excessive or prolonged stress, the neuron further adaptively reduces the number of available glutamate receptors by reducing dendrite length and spine number to protect itself from glutamate-induced cell death. Although this limits glutamatergic toxic effects on the neuron and may preserve the cell body, it essentially disconnects the neuron from other neurons by reducing the number of synaptic connections, thereby preventing cell death, but possibly precipitating anxiety or depressive disorders. ${ }^{115,120}$ Indeed, current prominent theories for the pathogenesis of anxiety disorders include the notion that the amygdala is disconnected from the tonic inhibiting influence of the prefrontal cortex; this is also seen in the striking reduction in neuronal processes evident in the neurobiology of depression (reviewed in Manji et al. ${ }^{121}$ ).

NMDA receptor antagonists appear to have neuroprotective properties in a number of studies. ${ }^{17,122}$ As noted above, the NR2B subunit of the NMDA receptor has recently been shown to be a critical element in the surface expression of NMDA receptors, ${ }^{119}$ and internalization of the NMDA receptor may be enhanced by drugs that downregulate the NR2B subunit (e.g., citalopram as described above), allowing the neuron to still respond to fear but be protected from excitotoxicity. Recent studies have found that lithium decreased NR2B phosphorylation, reducing NMDA receptor-mediated excitotoxicity $^{123}$ and increasing $\mathrm{N}$-acetyl-aspartate (NAA) and gray matter in the human brain. ${ }^{124,125}$ This again suggests that, by reducing the cell surface expression of NMDA receptors, these drugs may thereby reduce the sensitivity of the neuron to glutamate, and this decrease in glutamatergic neurotransmission may avert dendritic remodeling under stress conditions. ${ }^{54}$ In 1999 , a review ${ }^{12}$ noted a dampening of NMDA receptor function by antidepressant treatment, but queried as to its functional significance. Both antidepressants and NMDA antagonists decrease glutamatergic neurotransmission without the cell's shrinking or pulling back its dendrites, whether as protection from excitotoxicity or from another mechanism. It is possible that recovery from depression or anxiety disorders necessitates a restoration of a basal rate of neurogenesis, ${ }^{17,115,120,126}$ and thus that the adaptation or inhibition of NMDA receptors (functionally reducing 
glutamatergic neurotransmission) is necessary for the mechanism of action of antidepressant medications. ${ }^{12}$

\section{DRUGS WITH EFFECTS ON GLUTAMATERGIC NEUROTRANSMISSION}

We and others have also now tested several drugs that affect glutamatergic neurotransmission in patients with mood and anxiety disorders. Charney's group ${ }^{127,128}$ reported open-label efficacy for riluzole in patients with refractory depression and those with bipolar depression. Gorman's group ${ }^{129}$ presented similar uncontrolled data for riluzole in patients with GAD. Additionally, riluzole was reported effective in a case study of a patient with obsessive-compulsive disorder and major depression. ${ }^{130}$ Riluzole decreases glutamatergic neurotransmission, is neuroprotective, and is approved for the treatment of amyotrophic lateral sclerosis. Although its exact mechanism of action has yet to be elucidated, the following have been theorized: inactivation of voltage-dependent sodium channels; inactivation of P/Q-type calcium channels; direct inhibition of PKC; potentiation of AMPA receptor; agonism of $\mathrm{GABA}_{\mathrm{A}}$ receptors; downmodulation of the HPA axis; antagonism of the anxiogenic properties of the betacarboline FG 7142 in rats; neuroprotection in models of ischemia and in Parkinson's disease; stimulation of NGF, BDNF, and GDNF in cultured mouse astrocytes; and facilitating increase in clearance of glutamate from synaptic space through enhancement of reuptake in rat astrocytes. ${ }^{131-133}$ If riluzole continues to prove efficacious in ongoing larger, multicenter, double-blind, placebo-controlled studies, it will be even more crucial to understand its mechanism of action. As noted above, ketamine, an NMDA receptor antagonist, had a surprisingly prolonged antidepressant effect, ${ }^{93}$ but memantine, a drug that partially blocks the NMDA receptor and is approved for the treatment of Alzheimer's disease, ${ }^{134}$ did not appear efficacious in a placebo-controlled depression trial. ${ }^{135}$ Although we are not aware of any anxiety disorder trials yet published for memantine, a recent report ${ }^{136}$ found that memantine inhibited ethanol-induced upregulation of NMDA receptor subunits NR1, NR2A, and NR2B.

\section{METABOTROPIC GLUTAMATE RECEPTORS}

Multiple preclinical studies have shown that compounds that affect metabotropic glutamate receptors have efficacy in mood and anxiety disorders. What follows is a rough sketch of the actions of several of these receptors; for a more comprehensive description, please see the recent review by Swanson et al. ${ }^{137}$ Briefly, eight receptors are divided into three groups (group I, mGluR1/5; group II, mGluR2/3; and group III, mGluR4/ $6 / 7 / 8$ ). These G protein-coupled receptors serve to mod- ulate and fine tune glutamatergic neurotransmission and may allow for specific and discrete pharmacological interventions in a number of different psychiatric and neurological diseases (e.g., depression, anxiety, addiction, epilepsy, cerebral ischemia, pain, and Parkinson's disease). ${ }^{138-141}$ Regulation of the glutamatergic system by pharmacological derivatives of metabotropic agonists or antagonists is the area that some authors feel is most promising for new drug development. ${ }^{52,57}$

The group I receptors are primarily (though not exclusively) located postsynaptically and serve an excitatory role. Local amygdalar injection of group I agonists has been found to enhance startle responses and mediate anxiogenic effects in rats. ${ }^{142}$ Specifically, mGluR5 has been postulated to be required for fear memory formation and long-term potentiation in the amygdala. ${ }^{143}$ Most studies of antagonists of group I receptors have been carried out with 2-methyl-6-(phenylethynyl)pyridine (MPEP), which is selective for the mGlu5 receptor subtype. This compound has been shown to have anxiolytic potential in multiple rodent models of anxiety, ${ }^{144-146}$ disrupting acquisition and expression of fear conditioning in the amygdala and other regions, respectively. ${ }^{143,147}$ In general, compounds that antagonize (directly or allosterically) the generally postsynaptic and excitatory group I metabotropic receptors have shown efficacy in preclinical models of depression $^{140,141,145,148}$ and anxiety, ${ }^{14,149}$ and the literature suggests that mGluR1 blockade may reduce NMDAmediated neurotransmission. ${ }^{140}$ Accordingly, its activation may actually enhance NMDA receptor-mediated neuronal degradation. ${ }^{150}$ Finally, chronic treatment with the tricyclic antidepressant imipramine caused functional downregulation of mGluR1in the CA1 region of mouse hippocampi ${ }^{151}$ Interestingly, acute imipramine had no effect on attenuating mGluR1 response to an agonist; after 7 days, however, an effect emerged that was maximized at 14 days and further unchanged at 21 days, somewhat paralleling the time course of action of imipramine in humans.

In contrast to the postsynaptic/excitatory group I receptors, group II receptors exist at both pre- and postsynaptic sites and are inhibitory. Whereas it has been shown that their presynaptic activation serves to decrease glutamate release (and that of other neurotransmitters) ${ }^{152}$ via a negative feedback mechanism, it has also been argued that postsynaptic agonism limits the excitability of target neurons. Multiple animal and human studies have used these findings to assess the effects of glutamatergic modulation in models of anxiety disorders, with agonist-mediated anxiolysis and antagonists increasing anxiety. Gorman's group ${ }^{153}$ reported that LY354740, a group II metabotropic (mGluR 2/3) agonist, is anxiolytic in a nonhuman primate model of yohimbine-induced anxiety; in these primates, post-treatment plasma cortisol 
was reduced by $\sim 50 \%$. This same compound was as effective as alprazolam in preventing lactate-induced anxiety in panic-prone rats, ${ }^{154}$ in blocking fear-potentiated startle in rats ${ }^{155}$ and humans, ${ }^{138}$ and $\mathrm{CO}_{2}$-provoked anxiety in human patients with panic disorder. ${ }^{156} \mathrm{~A}$ recent report shows changes in group I and group II metabotropic receptor expression in the prefrontal cortex of rats exposed to an impoverished rearing environment, ${ }^{157}$ and just as imipramine causes downregulation of mGluR1 receptors, it also mediated upregulation of hippocampal mGluR2/3. ${ }^{158}$ Finally, group II metabotropic agonists have been shown, like lamotrigine (see above), to decrease the motor and cognitive effects of NMDA antagonists such as phencyclidine (which increases glutamate neurotransmission via non-NMDA receptors. $)^{159}$

There have been fewer studies of group III metabotropic receptors in anxiety and depression due to a paucity of pharmacological tools, and most have employed genetic alterations. A study ${ }^{160}$ using mice with a targeted deletion of the gene for mGluR7 (-/-) showed these animals to be less immobile in the tail suspension and forced swim tests (widely used to predict antidepressant activity) as well as to display less anxiety in the lightdark box, elevated plus maze, staircase test, and stressinduced hyperthermia test. In contrast, a study using mGluR8 (primarily presynaptic) receptor-deficient mice showed increased anxiety-related behaviors on the elevated plus maze but did not demonstrate changes in gross behavior or in the function of the autonomic nervous or somatomotor systems. ${ }^{161}$

The major glutamatergic research to date has focused on the development of compounds that act within the NMDA complex; however, it is likely that the fine tuning of the system with drugs that affect metabotropic receptors will ultimately attenuate excess glutamatergic neurotransmission in discrete brain areas while leaving unaffected normal transmission and thus minimize adverse effects.

\section{NEUROIMAGING OF GLUTAMATERGIC FUNCTION IN ANXIETY DISORDERS}

Despite the growing amount of preclinical data and the development of novel therapeutics, there is still a dearth of tools to assess the effectiveness of our interventions. As such, one or more objective biological markers to guide treatment decisions would be a welcome addition to any area of psychiatry. ${ }^{162}$ Although we will limit our discussion to neuroimaging markers of glutamate in anxiety disorders, this is not to imply that research has stalled on other biomarkers (including genetic vulnerabilities) for these conditions; rather, the field is progressing at such a rapid rate that we only have space here for a brief presentation of a topic salient to our discussion.
The direct measurement of brain chemicals using in vivo magnetic resonance spectroscopy (MRS) provides a promising lead to help guide treatment decisions. The largest peak detected in primate brain by proton $\left({ }^{1} \mathrm{H}\right)$ MRS is NAA, an amino acid derived from $\mathrm{N}$-acetylaspartate-glutamate, ${ }^{163,164}$ which is associated with steady-state glutamate concentrations and neuronal integrity in specific brain regions. Although originally believed to be a neuronal specific marker, NAA has recently been found in oligodendrocytes and other glialderived elements. ${ }^{165}$ NAA concentration is reduced in classic degenerative brain disorders like Huntington's disease, ${ }^{166}$ Alzheimer's disease, ${ }^{167}$ and HIV-associated dementia. ${ }^{168}$ It has also been shown to be abnormal in key brain areas in several psychiatric illnesses including schizophrenia, ${ }^{169}$ depression, ${ }^{170}$ and anxiety disorders, ${ }^{4,171-173}$ although the directionality of NAA in these diseases has been more variable than in the neurodegenerative disorders. We and others have shown, for example, decreased NAA in the superior temporal gyrus of patients with schizophrenia, ${ }^{174}$ decreased NAA in the anterior cingulate of monkeys exposed to early rearing stress, ${ }^{175}$ reduced NAA concentrations in the temporal cortex of rats reared in isolation, ${ }^{176}$ and increased NAA in the dorsolateral prefrontal cortex of patients with GAD. ${ }^{4}$ Importantly, NAA appears to be vulnerable to psychosocial stress. Additional preliminary data from the latter study also showed that cognitive behavioral therapy decreases NAA in the dorsolateral prefrontal cortex in patients with GAD. Interestingly, in a separate cohort of patients with GAD, Mathew et al. ${ }^{129}$ observed that baseline reductions in NAA in the hippocampus predicted response to riluzole after 2 months of treatment. Additionally, riluzole has been shown to increase NAA in patients with ALS. These findings raise the possibility that the stress-induced changes in dendritic morphology that we see in rats exposed to chronic stress are related to reduced NAA concentration, and therefore that reduced NAA in human MRS studies also represents stress-induced dendritic remodeling.

In addition to the high peak of NAA in proton MRS, a smaller peak known as GLX can be detected; this is a combination of glutamate, glutamine, and GABA. ${ }^{57}$ Studies have shown changes in the GLX peak in patients with schizophrenia that support theories of glutamate alteration in that disorder. ${ }^{174,177,178}$ Also, in our adult monkeys exposed to adverse rearing stress, we found an elevated GLX peak in the anterior cingulate that correlated significantly with reduced NAA concentration. ${ }^{175}$ Thus, we might conclude that adverse rearing stress increases excitatory neurotransmission that leads to a reduction in neural integrity as measured by the NAA peak; important to consider is the persistence of this hyperglutamatergic state, long after the initial rearing stress. However, we cannot rule out a change in GABA 
concentration in this experiment nor make cause-andeffect conclusions based on a correlation. Investigators at Yale University, however, have used the MRS technique of J-editing to show a reduced concentration of GABA in the occipital cortex of patients with depression and with panic disorder. ${ }^{179,180}$ More recently, they have found elevated concentrations of glutamate in patients with MDD, with significant negative correlations between glutamate and GABA. $^{181}$

13C MRS is an even more powerful technique to measure glutamate activity in the brain and offers a means of capturing dynamic metabolite flux rates of glutamate. ${ }^{182,183}$ This technique offers the possibility of monitoring dynamic changes in the glutamate/glutamine shuttle between astrocytes and neurons in discrete brain regions, and it could be an excellent method for monitoring the effects of glutamatergic modulating drugs for mood and anxiety disorders.

\section{FUTURE DIRECTIONS}

It is clear that the neurobiology of anxiety disorders is being unveiled at a rapid rate and will lead to many advances in the treatment of these seriously impairing conditions. What we have presented here is but a snapshot of some of the novel therapies that have been based on recent groundbreaking work. There is an exciting amount of research being undertaken, and the discovery of glutamatergic mechanisms in anxiety disorders may allow the ultimate elucidation of a single common pathway for their origin and treatment. As is usual in science, this excitement extends even beyond the field of anxiety disorders; witness the well known association between anxiety and pain, which may also be the product of glutamatergic dysregulation. Pain, seemingly out of nowhere, for which no medical cause can be found, is not uncommon in anxiety disorders and is frequently ameliorated with treatment of the psychiatric malady. There is an increasingly bolstered association between pain (including chronic varieties) and central glutamatergic dysfunction, such that NMDA antagonists, and more specifically NR2B antagonists, are being studied for its treatment; NR2B antagonists are antinociceptive at doses below those that impair motor coordination. ${ }^{184}$ Additionally, studies have shown that group I metabotropic receptors are involved in the development and maintenance of pronociceptive hypersensitivity, and group I receptor antagonists are antinociceptive, as are agonists for group II receptors, in keeping with their respective effects on anxiety (see Chizh ${ }^{185}$ for a recent review). We include these final points within the Future Directions section as an impetus to merge different fields of existing research to develop studies to address common neurobiological mechanisms of illness behavior.
Disclosures: Neither author has any pharma grant support to disclose.

\section{REFERENCES}

1. MacLean PD. The triune brain in evolution: role in paleocerebral functions. New York: Plenum US, 1990.

2. LeDoux J. The emotional brain: the mysterious underpinnings of emotional life. New York: Simon \& Schuster, 1996.

3. Baxter LR Jr, Phelps ME, Mazziotta JC, Guze BH, Schwartz JM, Selin CE. Local cerebral glucose metabolic rates in obsessivecompulsive disorder. A comparison with rates in unipolar depression and in normal controls. Arch Gen Psychiatry 44:211-218, 1987.

4. Mathew SJ, Mao X, Coplan JD, Smith EL, Sackeim HA, Gorman JM, et al. Dorsolateral prefrontal cortical pathology in generalized anxiety disorder: a proton magnetic resonance spectroscopic imaging study. Am J Psychiatry 161:1119-1121, 2004.

5. Hollander E, Dell'Osso B. New developments in an evolving field. Psychiatric Times 2005.

6. Germine M. The concept of energy in Freud's project for a scientific psychology. Ann NY Acad Sci 843:80-90, 1998.

7. Hall WD, Mant A, Mitchell PB, Rendle VA, Hickie IB, McManus P. Association between antidepressant prescribing and suicide in Australia, 1991-2000: trend analysis. BMJ 326:1008, 2003.

8. Isacsson G, Bergman U, Rich CL. Epidemiological data suggest antidepressants reduce suicide risk among depressives. J Affect Disord 41:1-8, 1996.

9. Rihmer Z. Can better recognition and treatment of depression reduce suicide rates? A brief review. Eur Psychiatry 16:406-409, 2001.

10. Ramboz S, Oosting R, Amara DA, Kung HF, Blier P, Mendelsohn M, et al. Serotonin receptor 1A knockout: an animal model of anxiety-related disorder. Proc Natl Acad Sci USA 95:1447614481, 1998.

11. Greden JF. Unmet need: what justifies the search for a new antidepressant? J Clin Psychiatry 63 [Suppl 2]:3-7, 2002.

12. Skolnick P. Antidepressants for the new millennium. Eur J Pharmacol 375:31-40, 1999.

13. Allgulander C, Dahl AA, Austin C, Morris PL, Sogaard JA, Fayyad R, et al. Efficacy of sertraline in a 12-week trial for generalized anxiety disorder. Am J Psychiatry 161:1642-1649, 2004.

14. Liebowitz MR, Gelenberg AJ, Munjack D. Venlafaxine extended release vs placebo and paroxetine in social anxiety disorder. Arch Gen Psychiatry 62:190-198, 2005.

15. Moncrieff J, Wessely S, Hardy R. Active placebos versus antidepressants for depression. Cochrane Database Syst Rev 1:CD003012, 2004.

16. Otto MW, Tuby KS, Gould RA, McLean RY, Pollack MH. An effect-size analysis of the relative efficacy and tolerability of serotonin selective reuptake inhibitors for panic disorder. Am J Psychiatry 158:1989-1992, 2001.

17. Manji HK, Quiroz JA, Sporn J, Payne JL, Denicoff K, Gray AN et al. Enhancing neuronal plasticity and cellular resilience to develop novel, improved therapeutics for difficult-to-treat depression. Biol Psychiatry 53:707-742, 2003.

18. Ballenger JC. Remission rates in patients with anxiety disorders treated with paroxetine. J Clin Psychiatry 65:1696-1707, 2004.

19. Barbey JT, Roose SP. SSRI safety in overdose. J Clin Psychiatry 59 [Suppl 15]:42-48, 1998.

20. Rosen RC, Lane RM, Menza M. Effects of SSRIs on sexual function: a critical review. J Clin Psychopharmacol 19:67-85, 1999.

21. Harris B, Young J, Hughes B. Comparative effects of seven antidepressant regimes on appetite, weight and carbohydrate preference. Br J Psychiatry 148:590-592, 1986.

22. Hirschfeld RM. History and evolution of the monoamine hypothesis of depression. J Clin Psychiatry 61 [Suppl 6]:4-6, 2000.

23. McEwen BS, Olie JP. Neurobiology of mood, anxiety, and emotions as revealed by studies of a unique antidepressant: tianeptine. Mol Psychiatry 2005. 
24. Petrie RX, Reid IC, Stewart CA. The N-methyl-D-aspartate receptor, synaptic plasticity, and depressive disorder. A critical review. Pharmacol Ther 87:11-25, 2000.

25. Sanger D, Willner P, Bergman J. Applications of behavioural pharmacology in drug discovery. Behav Pharmacol 14:363-367, 2003.

26. Krystal JH, Sanacora G, Blumberg H, Anand A, Charney DS, Marek G, et al. Glutamate and GABA systems as targets for novel antidepressant and mood-stabilizing treatments. Mol Psychiatry 7 [Suppl 1]:S71-S80, 2002.

27. Kendler KS, Karkowski-Shuman L. Stressful life events and genetic liability to major depression: genetic control of exposure to the environment? Psychol Med 27:539-547, 1997.

28. Santarelli L, Gobbi G, Debs PC, Sibille ET, Blier P, Hen R, et al. Genetic and pharmacological disruption of neurokinin 1 receptor function decreases anxiety-related behaviors and increases serotonergic function. Proc Natl Acad Sci USA 98:1912-1917, 2001.

29. Heilig M. The NPY system in stress, anxiety and depression. Neuropeptides 38:213-224, 2004.

30. Zhuang X, Gross C, Santarelli L, Compan V, Trillat AC, Hen R. Altered emotional states in knockout mice lacking 5-HT1A or 5-HT1B receptors. Neuropsychopharmacology 21:52S-60S, 1999.

31. Gross C, Hen R. The developmental origins of anxiety. Nat Rev Neurosci 5:545-552, 2004.

32. Morgan CA 3rd, Rasmusson AM, Wang S, Hoyt G, Hauger RL, Hazlett G. Neuropeptide-Y, cortisol, and subjective distress in humans exposed to acute stress: replication and extension of previous report. Biol Psychiatry 52:136-142, 2002.

33. Atack JR. The benzodiazepine binding site of GABA(A) receptors as a target for the development of novel anxiolytics. Expert Opin Investig Drugs 14:601-618, 2005.

34. McKernan RM, Rosahl TW, Reynolds DS, Sur C, Wafford KA, Atack JR, et al. Sedative but not anxiolytic properties of benzodiazepines are mediated by the $\mathrm{GABA}(\mathrm{A})$ receptor $\alpha 1$ subtype. Nat Neurosci 3:587-592, 2000.

35. Habib KE, Weld KP, Rice KC, Pushkas J, Champoux M, Listwak $\mathrm{S}$, et al. Oral administration of a corticotropin-releasing hormone receptor antagonist significantly attenuates behavioral, neuroendocrine, and autonomic responses to stress in primates. Proc Natl Acad Sci USA 97:6079-6084, 2000.

36. Coplan JD, Andrews MW, Rosenblum LA, Owens MJ, Friedman S, Gorman JM, et al. Persistent elevations of cerebrospinal fluid concentrations of corticotropin-releasing factor in adult nonhuman primates exposed to early-life stressors: implications for the pathophysiology of mood and anxiety disorders. Proc Natl Acad Sci USA 93:1619-1623, 1996.

37. Cahill L, Prins B, Weber M, McGaugh JL. $\beta$-Adrenergic activation and memory for emotional events. Nature 371:702-704, 1994.

38. Pitman RK, Sanders KM, Zusman RM, Healy AR, Cheema F, Lasko NB, et al. Pilot study of secondary prevention of posttraumatic stress disorder with propranolol. Biol Psychiatry 51:189192, 2002.

39. Paul IA, Skolnick P. Glutamate and depression: clinical and preclinical studies. Ann NY Acad Sci 1003:250-272, 2003.

40. Skolnick P, Layer RT, Popik P, Nowak G, Paul IA, Trullas R. Adaptation of N-methyl-D-aspartate (NMDA) receptors following antidepressant treatment: implications for the pharmacotherapy of depression. Pharmacopsychiatry 29:23-26, 1996.

41. Mathew SJ, Coplan JD, Schoepp DD, Smith EL, Rosenblum LA, Gorman JM. Glutamatehypothalamic-pituitary-adrenal axis interactions: implications for mood and anxiety disorders. CNS Spectr 6:555-564, 2001.

42. Caspi A, Sugden K, Moffitt TE, Taylor A, Craig IW, Harrington $\mathrm{H}$, et al. Influence of life stress on depression: moderation by a polymorphism in the 5-HTT gene. Science 301:386-389, 2003.

43. Pezawas L, Meyer-Lindenberg A, Drabant EM, Verchinski BA, Munoz KE, Kolachana BS, et al. 5-HTTLPR polymorphism impacts human cingulate-amygdala interactions: a genetic susceptibility mechanism for depression. Nat Neurosci 8:828-834, 2005.

44. Bifulco A, Bernazzani O, Moran PM, Ball C. Lifetime stressors and recurrent depression: preliminary findings of the Adult Life
Phase Interview (ALPHI). Soc Psychiatry Psychiatr Epidemiol 35:264-275, 2000.

45. Duman RS, Heninger GR, Nestler EJ. A molecular and cellular theory of depression. Arch Gen Psychiatry 54:597-606, 1997.

46. Bagley J, Moghaddam B. Temporal dynamics of glutamate efflux in the prefrontal cortex and in the hippocampus following repeated stress: effects of pretreatment with saline or diazepam. Neuroscience 77:65-73, 1997.

47. McEwen BS. Stress and hippocampal plasticity. Annu Rev Neurosci 22:105-122, 1999.

48. Moghaddam B. Stress preferentially increases extraneuronal levels of excitatory amino acids in the prefrontal cortex: comparison to hippocampus and basal ganglia. J Neurochem 60:1650-1657, 1993.

49. Moghaddam B, Bolinao ML, Stein-Behrens B, Sapolsky R. Glucocorticoids mediate the stress-induced extracellular accumulation of glutamate. Brain Res 655:251-254, 1994.

50. Moghaddam B. Stress activation of glutamate neurotransmission in the prefrontal cortex: implications for dopamine-associated psychiatric disorders. Biol Psychiatry 51:775-787, 2002.

51. Coyle JT, Leski ML, Morrison JH. The diverse roles of L-glutamic acid in brain signal transduction. In: Neuropsychopharmacology: the fifth generation of progress (Davis KL, Charney D, Coyle JT, Nemeroff C, eds), Ed 5, pp 71-90. Philadelphia: Lippincott Williams \& Wilkins, 2002.

52. Bergink V, van Megen HJ, Westenberg HG. Glutamate and anxiety. Eur Neuropsychopharmacol 14:175-183, 2004.

53. Bliss TV, Collingridge GL. A synaptic model of memory: longterm potentiation in the hippocampus. Nature 361:31-39, 1993.

54. Magarinos AM, McEwen BS. Stress-induced atrophy of apical dendrites of hippocampal CA3c neurons: involvement of glucocorticoid secretion and excitatory amino acid receptors. Neuroscience 69:89-98, 1995.

55. Kemp JA, McKernan RM. NMDA receptor pathways as drug targets. Nat Neurosci 5 [Suppl]:1039-1042, 2002.

56. Rothstein JD, Jin L, Dykes-Hoberg M, Kuncl RW. Chronic inhibition of glutamate uptake produces a model of slow neurotoxicity. Proc Natl Acad Sci USA 90:6591-6595, 1993.

57. Sanacora G, Rothman DL, Mason G, Krystal JH. Clinical studies implementing glutamate neurotransmission in mood disorders. Ann NY Acad Sci 1003:292-308, 2003.

58. Davis M, Whalen PJ. The amygdala: vigilance and emotion. Mol Psychiatry 6:13-34, 2001.

59. LeDoux JE. Emotion circuits in the brain. Annu Rev Neurosci 23:155-184, 2000.

60. Davis M, Myers KM, Chhatwal J, Ressler KJ. Pharmacological treatments that facilitate extinction of fear: relevance to psychotherapy. NeuroRx 3:82-96, 2006.

61. Rogan MT, Staubli UV, LeDoux JE. Fear conditioning induces associative long-term potentiation in the amygdala. Nature 390: 604-607, 1997.

62. Walker DL, Davis M. The role of amygdala glutamate receptors in fear learning, fearpotentiated startle, and extinction. Pharmacol Biochem Behav 71:379-392, 2002.

63. Davis M, Rainnie D, Cassell M. Neurotransmission in the rat amygdala related to fear and anxiety. Trends Neurosci 17:208214, 1994.

64. Mathew SJ, Coplan JD, Gorman JM. Neurobiological mechanisms of social anxiety disorder. Am J Psychiatry 158:15581567, 2001.

65. Phan KL, Wager T, Taylor SF, Liberzon I. Functional neuroanatomy of emotion: a metaanalysis of emotion activation studies in PET and fMRI. Neuroimage 16:331-348, 2002.

66. Drevets WC. Neuroimaging abnormalities in the amygdala in mood disorders. Ann NY Acad Sci 985:420-444, 2003.

67. van den Heuvel OA, Veltman DJ, Groenewegen HJ, Witter MP, Merkelbach J, Cath DC, et al. Disorder-specific neuroanatomical correlates of attentional bias in obsessive-compulsive disorder, panic disorder, and hypochondriasis. Arch Gen Psychiatry 62: 922-933, 2005.

68. Rauch SL, Shin LM, Wright CI. Neuroimaging studies of amygdala function in anxiety disorders. Ann NY Acad Sci 985:389410, 2003. 
69. Rauch SL, Whalen PJ, Shin LM, McInerney SC, Macklin ML, Lasko NB, et al. Exaggerated amygdala response to masked facial stimuli in posttraumatic stress disorder: a functional MRI study. Biol Psychiatry 47:769-776, 2000.

70. Falls WA, Miserendino MJ, Davis M. Extinction of fear-potentiated startle: blockade by infusion of an NMDA antagonist into the amygdala. $J$ Neurosci 12:854-863, 1992.

71. Kim M, McGaugh JL. Effects of intra-amygdala injections of NMDA receptor antagonists on acquisition and retention of inhibitory avoidance. Brain Res 585:35-48, 1992.

72. Miserendino MJ, Sananes CB, Melia KR, Davis M. Blocking of acquisition but not expression of conditioned fear-potentiated startle by NMDA antagonists in the amygdala. Nature 345:716718, 1990.

73. Rodrigues SM, Schafe GE, LeDoux JE. Intra-amygdala blockade of the NR2B subunit of the NMDA receptor disrupts the acquisition but not the expression of fear conditioning. J Neurosci 21:6889-6896, 2001

74. Walker DL, Ressler KJ, Lu KT, Davis M. Facilitation of conditioned fear extinction by systemic administration or intra-amygdala infusions of D-cycloserine as assessed with fear-potentiated startle in rats. $J$ Neurosci 22:2343-2351, 2002.

75. Ressler KJ, Rothbaum BO, Tannenbaum L, Anderson P, Graap $\mathrm{K}$, Zimand E, et al. Cognitive enhancers as adjuncts to psychotherapy: use of D-cycloserine in phobic individuals to facilitate extinction of fear. Arch Gen Psychiatry 61:1136-1144, 2004.

76. Burghardt NS, Sullivan GM, McEwen BS, Gorman JM, LeDoux JE. The selective serotonin reuptake inhibitor citalopram increases fear after acute treatment but reduces fear with chronic treatment: a comparison with tianeptine. Biol Psychiatry 55:1171-1178, 2004.

77. N. Burghardt. Insights into panic disorder from fear conditioning models. American College of Neuropsychopharmacology, 43rd Annual Meeting Abstracts, 2004.

78. Boyer PA, Skolnick P, Fossom LH. Chronic administration of imipramine and citalopram alters the expression of NMDA receptor subunit mRNAs in mouse brain. A quantitative in situ hybridization study. J Mol Neurosci 10:219-233, 1998.

79. Nowak G, Legutko B, Skolnick P, Popik P. Adaptation of cortical NMDA receptors by chronic treatment with specific serotonin reuptake inhibitors. Eur J Pharmacol 342:367-370, 1998.

80. Paul IA, Nowak G, Layer RT, Popik P, Skolnick P. Adaptation of the N-methyl-D-aspartate receptor complex following chronic antidepressant treatments. J Pharmacol Exp Ther 269:95-102, 1994.

81. Watkins CJ, Pei Q, Newberry NR. Differential effects of electroconvulsive shock on the glutamate receptor mRNAs for NR2A, NR2B and mGluR5b. Brain Res Mol Brain Res 61:108-113, 1998.

82. Liu L, Wong TP, Pozza MF, Lingenhoehl K, Wang Y, Sheng M, et al. Role of NMDA receptor subtypes in governing the direction of hippocampal synaptic plasticity. Science 304:1021-1024, 2004.

83. Berberich S, Punnakkal P, Jensen V, Pawlak V, Seeburg PH, Hvalby $\mathrm{O}$, et al. Lack of NMDA receptor subtype selectivity for hippocampal long-term potentiation. J Neurosci 25:6907-6910, 2005.

84. Yang CH, Huang CC, Hsu KS. Behavioral stress enhances hippocampal CA1 long-term depression through the blockade of the glutamate uptake. J Neurosci 25:4288-4293, 2005.

85. Rothstein JD, Patel S, Regan MR, Haenggeli C, Huang YH, Bergles DE, et al. $\beta$-Lactam antibiotics offer neuroprotection by increasing glutamate transporter expression. Nature 433:73-77, 2005.

86. Maragakis NJ, Rothstein JD. Glutamate transporters in neurologic disease. Arch Neurol 58:365-370, 2001.

87. Nagy J. The NR2B subtype of NMDA receptor: a potential target for the treatment of alcohol dependence. Curr Drug Targets CNS Neurol Disord 3:169-179, 2004.

88. Lopez de Armentia M, Sah P. Development and subunit composition of synaptic NMDA receptors in the amygdala: NR2B synapses in the adult central amygdala. $J$ Neurosci 23:6876-6883, 2003.
89. Liu XB, Murray KD, Jones EG. Switching of NMDA receptor 2A and $2 \mathrm{~B}$ subunits at thalamic and cortical synapses during early postnatal development. J Neurosci 24:8885-8895, 2004.

90. Rosenberg DR, MacMaster FP, Keshavan MS, Fitzgerald KD, Stewart CM, Moore GJ. Decrease in caudate glutamatergic concentrations in pediatric obsessive-compulsive disorder patients taking paroxetine. J Am Acad Child Adolesc Psychiatry 39:1096$1103,2000$.

91. Bonanno G, Giambelli R, Raiteri L, Tiraboschi E, Zappettini S, Musazzi L, et al. Chronic antidepressants reduce depolarizationevoked glutamate release and protein interactions favoring formation of SNARE complex in hippocampus. J Neurosci 25 : 3270-3279, 2005.

92. Michael-Titus AT, Bains S, Jeetle J, Whelpton R. Imipramine and phenelzine decrease glutamate overflow in the prefrontal cortex-a possible mechanism of neuroprotection in major depression? Neuroscience 100:681-684, 2000.

93. Berman RM, Cappiello A, Anand A, Oren DA, Heninger GR, Charney DS, et al. Antidepressant effects of ketamine in depressed patients. Biol Psychiatry 47:351-354, 2000.

94. Layer RT, Popik P, Olds T, Skolnick P. Antidepressant-like actions of the polyamine site NMDA antagonist, eliprodil (SL82.0715). Pharmacol Biochem Behav 52:621-627, 1995.

95. Nowak G, Trullas R, Layer RT, Skolnick P, Paul IA. Adaptive changes in the N-methyl-D-aspartate receptor complex after chronic treatment with imipramine and 1-aminocyclopropanecarboxylic acid. J Pharmacol Exp Ther 265:1380-1386, 1993.

96. Papp M, Moryl E. Antidepressant-like effects of 1-aminocyclopropanecarboxylic acid and D-cycloserine in an animal model of depression. Eur J Pharmacol 316:145-151, 1996.

97. Trullas R, Skolnick P. Functional antagonists at the NMDA receptor complex exhibit antidepressant actions. Eur J Pharmacol 185:1-10, 1990.

98. Vale S, Espejel MA, Dominguez JC. Amantadine in depression. Lancet 2:437, 1971.

99. Xie Z, Commissaris RL. Anxiolytic-like effects of the noncompetitive NMDA antagonist MK 801. Pharmacol Biochem Behav 43:471-477, 1992.

100. Anand A, Charney DS, Oren DA, Berman RM, Hu XS, Cappiello A, et al. Attenuation of the neuropsychiatric effects of ketamine with lamotrigine: support for hyperglutamatergic effects of $\mathrm{N}$ methyl-D-aspartate receptor antagonists. Arch Gen Psychiatry 57:270-276, 2000.

101. Hertzberg MA, Butterfield MI, Feldman ME, Beckham JC, Sutherland SM, Connor KM, et al. A preliminary study of lamotrigine for the treatment of posttraumatic stress disorder. Biol Psychiatry 45:1226-1229, 1999.

102. Berlant J, van Kammen DP. Open-label topiramate as primary or adjunctive therapy in chronic civilian posttraumatic stress disorder: a preliminary report. J Clin Psychiatry 63:15-20, 2002.

103. Sapolsky RM. Glucocorticoids and hippocampal atrophy in neuropsychiatric disorders. Arch Gen Psychiatry 57:925-935, 2000.

104. Costa E, Silva JA. From restoration of neuroplasticity to the treatment of depression: clinical experience. Eur Neuropsychopharmacol 14 [Suppl 5]:S511-S521, 2004.

105. Czeh B, Michaelis T, Watanabe T, Frahm J, de Biurrun G, van Kampen M, et al. Stress induced changes in cerebral metabolites, hippocampal volume, and cell proliferation are prevented by antidepressant treatment with tianeptine. Proc Natl Acad Sci USA 98:12796-12801, 2001.

106. Watanabe Y, Gould E, Daniels DC, Cameron H, McEwen BS. Tianeptine attenuates stressinduced morphological changes in the hippocampus. Eur J Pharmacol 222:157-162, 1992.

107. Radley JJ, Sisti HM, Hao J, Rocher AB, McCall T, Hof PR, et al. Chronic behavioral stress induces apical dendritic reorganization in pyramidal neurons of the medial prefrontal cortex. Neuroscience 125:1-6, 2004.

108. Willner P, Muscat R, Papp M. Chronic mild stress-induced anhedonia: a realistic animal model of depression. Neurosci Biobehav Rev 16:525-534, 1992.

109. Cotter D, Mackay D, Landau S, Kerwin R, Everall I. Reduced glial cell density and neuronal size in the anterior cingulate cortex 
in major depressive disorder. Arch Gen Psychiatry 58:545-553, 2001.

110. Drevets WC. Neuroimaging studies of mood disorders. Biol Psychiatry 48:813-829, 2000.

111. Ongur D, Drevets WC, Price JL. Glial reduction in the subgenual prefrontal cortex in mood disorders. Proc Natl Acad Sci USA 95:13290-13295, 1998.

112. Rajkowska G, Miguel-Hidalgo JJ, Wei J, Dilley G, Pittman SD, Meltzer HY, et al. Morphometric evidence for neuronal and glial prefrontal cell pathology in major depression. Biol Psychiatry 45:1085-1098, 1999.

113. Sheline YI, Wang PW, Gado MH, Csernansky JG, Vannier MW. Hippocampal atrophy in recurrent major depression. Proc Natl Acad Sci USA 93:3908-3913, 1996.

114. Cratty MS, Birkle DL. N-methyl-D-aspartate (NMDA)-mediated corticotropin-releasing factor (CRF) release in cultured rat amygdala neurons. Peptides 20:93-100, 1999.

115. Duman RS. Synaptic plasticity and mood disorders. Mol Psychiatry 7 [Suppl 1]:S29-S34, 2002.

116. Carlson PJ, Singh JB, Zarate CA Jr, Drevets WC, Manji HK. Neural circuitry and neuroplasticity in mood disorders: insights for novel therapeutic targets. NeuroRx 3:22-41, 2006.

117. Zinebi F, Xie J, Liu J, Russell RT, Gallagher JP, McKernan MG, et al. NMDA currents and receptor protein are downregulated in the amygdala during maintenance of fear memory. J Neurosci 23:10283-10291, 2003.

118. Cottrell JR, Borok E, Horvath TL, Nedivi E. CPG2: a brain- and synapse-specific protein that regulates the endocytosis of glutamate receptors. Neuron 44:677-690, 2004.

119. Lavezzari G, McCallum J, Dewey CM, Roche KW. Subunitspecific regulation of NMDA receptor endocytosis. $J$ Neurosci 24:6383-6391, 2004.

120. Jacobs BL, Praag H, Gage FH. Adult brain neurogenesis and psychiatry: a novel theory of depression. Mol Psychiatry 5:262269, 2000.

121. Manji HK, Drevets WC, Charney DS. The cellular neurobiology of depression. Nat Med 7:541-547, 2001.

122. Skolnick P, Legutko B, Li X, Bymaster FP. Current perspectives on the development of non-biogenic amine-based antidepressants. Pharmacol Res 43:411-423, 2001.

123. Hashimoto R, Hough C, Nakazawa T, Yamamoto T, Chuang DM. Lithium protection against glutamate excitotoxicity in rat cerebral cortical neurons: involvement of NMDA receptor inhibition possibly by decreasing NR2B tyrosine phosphorylation. J Neurochem 80:589-597, 2002.

124. Moore GJ, Bebchuk JM, Hasanat K, Chen G, Seraji-Bozorgzad $\mathrm{N}$, Wilds IB, et al. Lithium increases $\mathrm{N}$-acetyl-aspartate in the human brain: in vivo evidence in support of bcl-2's neurotrophic effects? Biol Psychiatry 48:1-8, 2000.

125. Moore GJ, Bebchuk JM, Wilds IB, Chen G, Manji HK. Lithiuminduced increase in human brain grey matter. Lancet 356:12411242, 2000.

126. Santarelli L, Saxe M, Gross C, Surget A, Battaglia F, Dulawa S, et al. Requirement of hippocampal neurogenesis for the behavioral effects of antidepressants. Science 301:805-809, 2003.

127. Zarate CA Jr, Payne JL, Quiroz J, Sporn J, Denicoff KK, Luckenbaugh $\mathrm{D}$, et al. An open label trial of riluzole in patients with treatment-resistant major depression. Am J Psychiatry 161:171174,2004

128. Zarate CA Jr, Quiroz JA, Singh JB, Denicoff KD, De Jesus G, Luckenbaugh DA, et al. An open-label trial of the glutamatemodulating agent riluzole in combination with lithium for the treatment of bipolar depression. Biol Psychiatry 57:430-432, 2005.

129. Mathew SJ, Amiel JM, Coplan JD, Fitterling HA, Sackeim HA, Gorman JM. Riluzole in generalized anxiety disorder: an openlabel trial. Am J Psychiatry, in press.

130. Coric V, Milanovic S, Wasylink S, Patel P, Malison R, Krystal $\mathrm{JH}$. Beneficial effects of the antiglutamatergic agent riluzole in a patient diagnosed with obsessive-compulsive disorder and major depressive disorder. Psychopharmacology (Berl) 167:219-220, 2003.
131. Doble A. The pharmacology and mechanism of action of riluzole. Neurology 47:S233-S241, 1996.

132. Frizzo ME, Dall'Onder LP, Dalcin KB, Souza DO. Riluzole enhances glutamate uptake in rat astrocyte cultures. Cell Mol Neurobiol 24:123-128, 2004.

133. Kniest A, Wiesenberg C, Weber B, Colla M, Heuser I, Deuschle $\mathrm{M}$. The glutamate antagonist riluzole and its effects upon basal and stress-induced activity of the human hypothalamus-pituitaryadrenocortical system in elderly subjects. Neuropsychobiology 43:91-95, 2001.

134. Reisberg B, Doody R, Stoffler A, Schmitt F, Ferris S, Mobius HJ, et al. Memantine in moderate-to-severe Alzheimer's disease. $N$ Engl J Med 348:1333-1341, 2003.

135. Zarate CA Jr, Singh J, Quiroz, JA, Denicoff KD, De Jesus G, Luckenbaugh D, Manji HK, Charney DS. Memantine in major depression: a double-blind placebo-controlled study. Am J Psychiatry, in press.

136. Maler JM, Esselmann H, Wiltfang J, Kunz N, Lewczuk P, Reulbach U, et al. Memantine inhibits ethanol-induced NMDA receptor up-regulation in rat hippocampal neurons. Brain Res 1052: 152-162, 2005.

137. Swanson CJ, Bures M, Johnson MP, Linden AM, Monn JA, Schoepp DD. Metabotropic glutamate receptors as novel targets for anxiety and stress disorders. Nat Rev Drug Discov 4:131-144, 2005.

138. Grillon C, Cordova J, Levine LR, Morgan CA 3rd. Anxiolytic effects of a novel group II metabotropic glutamate receptor agonist (LY354740) in the fear-potentiated startle paradigm in humans. Psychopharmacology (Berl) 168:446-454, 2003.

139. Nicoletti F, Bruno V, Copani A, Casabona G, Knopfel T. Metabotropic glutamate receptors: a new target for the therapy of neurodegenerative disorders? Trends Neurosci 19:267-271, 1996.

140. Palucha A, Pilc A. On the role of metabotropic glutamate receptors in the mechanisms of action of antidepressants. Pol J Pharmacol 54:581-586, 2002.

141. Zarate CA Jr, Du J, Quiroz J, Gray NA, Denicoff KD, Singh J, et al. Regulation of cellular plasticity cascades in the pathophysiology and treatment of mood disorders: role of the glutamatergic system. Ann NY Acad Sci 1003:273-291, 2003.

142. Koch M. Microinjections of the metabotropic glutamate receptor agonist, trans-(+/-)-1-amino-cyclopentane-1,3-dicarboxylate (trans-ACPD) into the amygdala increase the acoustic startle response of rats. Brain Res 629:176-179, 1993.

143. Rodrigues SM, Bauer EP, Farb CR, Schafe GE, LeDoux JE. The group I metabotropic glutamate receptor mGluR5 is required for fear memory formation and long-term potentiation in the lateral amygdala. $J$ Neurosci 22:5219-5229, 2002.

144. Spooren WP, Vassout A, Neijt HC, Kuhn R, Gasparini F, Roux S, et al. Anxiolytic-like effects of the prototypical metabotropic glutamate receptor 5 antagonist 2-methyl-6-(phenylethynyl)pyridine in rodents. J Pharmacol Exp Ther 295:1267-1275, 2000.

145. Tatarczynska E, Klodzinska A, Chojnacka-Wojcik E, Palucha A, Gasparini F, Kuhn R, et al. Potential anxiolytic- and antidepressant-like effects of MPEP, a potent, selective and systemically active mGlu5 receptor antagonist. Br J Pharmacol 132:14231430, 2001

146. Busse CS, Brodkin J, Tattersall D, Anderson JJ, Warren N, Tehrani $\mathrm{L}$, et al. The behavioral profile of the potent and selective mGlu5 receptor antagonist 3-[(2-methyl-1,3-thiazol-4-yl)ethynyl]pyridine (MTEP) in rodent models of anxiety. Neuropsychopharmacology 29:1971-1979, 2004.

147. Schulz B, Fendt M, Gasparini F, Lingenhohl K, Kuhn R, Koch M. The metabotropic glutamate receptor antagonist 2-methyl-6-(phenylethynyl)-pyridine (MPEP) blocks fear conditioning in rats. Neuropharmacology 41:1-7, 2001.

148. Pilc A, Klodzinska A, Branski P, Nowak G, Palucha A, Szewczyk B, et al. Multiple MPEP administrations evoke anxiolytic- and antidepressant-like effects in rats. Neuropharmacology 43:181187, 2002.

149. Brodkin J, Busse C, Sukoff SJ, Varney MA. Anxiolytic-like activity of the mGluR5 antagonist MPEP a comparison with diazepam and buspirone. Pharmacol Biochem Behav 73:359366, 2002. 
150. Bruno V, Copani A, Knopfel T, Kuhn R, Casabona G, Dell'Albani $\mathrm{P}$ et al. Activation of metabotropic glutamate receptors coupled to inositol phospholipid hydrolysis amplifies NMDA induced neuronal degeneration in cultured cortical cells. Neuropharmacology 34:1089-1098, 1995.

151. Zahorodna A, Bijak M. An antidepressant-induced decrease in the responsiveness of hippocampal neurons to group I metabotropic glutamate receptor activation. Eur J Pharmacol 386:173-179, 1999.

152. Cartmell J, Schoepp DD. Regulation of neurotransmitter release by metabotropic glutamate receptors. J Neurochem 75:889-907, 2000.

153. Coplan JD, Mathew SJ, Smith EL, Trost RC, Scharf BA, Martinez J, et al. Effects of LY354740, a novel glutamatergic metabotropic agonist, on nonhuman primate hypothalamic-pituitary-adrenal axis and noradrenergic function. CNS Spectr 6:607-617, 2001.

154. Shekhar A, Keim SR. LY354740, a potent group II metabotropic glutamate receptor agonist prevents lactate-induced panic-like response in panic-prone rats. Neuropharmacology 39: 1139-1146, 2000.

155. Helton DR, Tizzano JP, Monn JA, Schoepp DD, Kallman MJ. Anxiolytic and side-effect profile of LY354740: a potent highly selective, orally active agonist for group II metabotropic glutamate receptors. J Pharmacol Exp Ther 284:651-660, 1998.

156. Levine LR, Gaydos B, Sheehan DV, Goddard A, Feighner J, Potter WZ, et al. The mGlu2/3 receptor agonist, LY354740, reduces panic anxiety induced by $\mathrm{CO} 2$ challenge in patients diagnosed with panic disorder. Neuropharmacology 43:294-294, 2002.

157. Melendez RI, Gregory ML, Bardo MT, Kalivas PW. Impoverished rearing environment alters metabotropic glutamate receptor expression and function in the prefrontal cortex. Neuropsychopharmacology 29:1980-1987, 2004.

158. Matrisciano F, Storto M, Ngomba RT, Cappuccio I, Caricasole A, Scaccianoce $\mathrm{S}$, et al. Imipramine treatment up-regulates the expression and function of mGlu2/3 metabotropic glutamate receptors in the rat hippocampus. Neuropharmacology 42:1008-1015, 2002.

159. Moghaddam B, Adams BW. Reversal of phencyclidine effects by a group II metabotropic glutamate receptor agonist in rats. Science 281:1349-1352, 1998.

160. Cryan JF, Kelly PH, Neijt HC, Sansig G, Flor PJ, van Der Putten $\mathrm{H}$. Antidepressant and anxiolytic-like effects in mice lacking the group III metabotropic glutamate receptor mGluR7. Eur J Neurosci 17:2409-2417, 2003.

161. Linden AM, Johnson BG, Peters SC, Shannon HE, Tian M, Wang $\mathrm{Y}$, et al. Increased anxiety-related behavior in mice deficient for metabotropic glutamate 8 (mGlu8) receptor. Neuropharmacology 43:251-259, 2002.

162. Blasi G, Bertolino A. Imaging genomics and response to treatment with antipsychotics in schizophrenia. NeuroRx 3:117-130, 2006.

163. Coyle JT. The nagging question of the function of $\mathrm{N}$-acetylaspartylglutamate. Neurobiol Dis 4:231-238, 1997.

164. Lyoo IK, Renshaw PF. Magnetic resonance spectroscopy: current and future applications in psychiatric research. Biol Psychiatry 51:195-207, 2002.

165. Bhakoo KK, Pearce D. In vitro expression of $\mathrm{N}$-acetyl aspartate by oligodendrocytes: implications for proton magnetic resonance spectroscopy signal in vivo. J Neurochem 74:254-262, 2000.

166. Sanchez-Pernaute R, Garcia-Segura JM, del Barrio Alba A, Viano J, de Yebenes JG. Clinical correlation of striatal ${ }^{1} \mathrm{H}$ MRS changes in Huntington's disease. Neurology 53:806-812, 1999.

167. Kantarci K, Jack CR Jr. Neuroimaging in Alzheimer disease: an evidence-based review. Neuroimaging Clin N Am 13:197-209, 2003.

168. Sacktor N, Skolasky RL, Ernst T, Mao X, Selnes O, Pomper MG, et al. A multicenter study of two magnetic resonance spectros- copy techniques in individuals with HIV dementia. J Magn Reson Imaging 21:325-333, 2005.

169. Kegeles LS, Humaran TJ, Mann JJ. In vivo neurochemistry of the brain in schizophrenia as revealed by magnetic resonance spectroscopy. Biol Psychiatry 44:382-398, 1998.

170. Auer DP, Putz B, Kraft E, Lipinski B, Schill J, Holsboer F. Reduced glutamate in the anterior cingulate cortex in depression: an in vivo proton magnetic resonance spectroscopy study. Biol Psychiatry 47:305-313, 2000.

171. Breiter HC, Rauch SL, Kwong KK, Baker JR, Weisskoff RM, Kennedy DN, et al. Functional magnetic resonance imaging of symptom provocation in obsessive-compulsive disorder. Arch Gen Psychiatry 53:595-606, 1996.

172. Dager SR, Marro KI, Richards TL, Metzger GD. Preliminary application of magnetic resonance spectroscopy to investigate lactate-induced panic. Am J Psychiatry 151:57-63, 1994.

173. Phan KL, Fitzgerald DA, Cortese BM, Seraji-Bozorgzad N, Tancer ME, Moore GJ. Anterior cingulate neurochemistry in social anxiety disorder: ${ }^{1} \mathrm{H}-\mathrm{MRS}$ at 4 Tesla. Neuroreport $16: 183$ 186, 2005.

174. Kegeles LS, Shungu DC, Anjilvel S, Chan S, Ellis SP, Xanthopoulos E, et al. Hippocampal pathology in schizophrenia: magnetic resonance imaging and spectroscopy studies. Psychiatry Res 98:163-175, 2000.

175. Mathew SJ, Shungu DC, Mao X, Smith EL, Perera GM, Kegeles LS, et al. A magnetic resonance spectroscopic imaging study of adult nonhuman primates exposed to early-life stressors. Biol Psychiatry 54:727-735, 2003.

176. Harte MK, Powell SB, Reynolds LM, Swerdlow NR, Geyer MA, Reynolds GP. Reduced N-acetyl-aspartate in the temporal cortex of rats reared in isolation. Biol Psychiatry 56:296-299, 2004.

177. Block W, Bayer TA, Tepest R, Traber F, Rietschel M, Muller DJ, et al. Decreased frontal lobe ratio of $\mathrm{N}$-acetyl aspartate to choline in familial schizophrenia: a proton magnetic resonance spectroscopy study. Neurosci Lett 289:147-151, 2000.

178. Ohrmann P, Siegmund A, Suslow T, Spitzberg K, Kersting A, Arolt $\mathrm{V}$, et al. Evidence for glutamatergic neuronal dysfunction in the prefrontal cortex in chronic but not in first-episode patients with schizophrenia: a proton magnetic resonance spectroscopy study. Schizophr Res 73:153-157, 2005.

179. Goddard AW, Mason GF, Almai A, Rothman DL, Behar KL, Petroff OA, et al. Reductions in occipital cortex GABA levels in panic disorder detected with $1 \mathrm{~h}$-magnetic resonance spectroscopy. Arch Gen Psychiatry 58:556-561, 2001.

180. Sanacora G, Mason GF, Rothman DL, Behar KL, Hyder F, Petroff OA, et al. Reduced cortical $\gamma$-aminobutyric acid levels in depressed patients determined by proton magnetic resonance spectroscopy. Arch Gen Psychiatry 56:1043-1047, 1999.

181. Sanacora G, Gueorguieva R, Epperson CN, Wu YT, Appel M, Rothman DL, et al. Subtypespecific alterations of $\gamma$-aminobutyric acid and glutamate in patients with major depression. Arch Gen Psychiatry 61:705-713, 2004.

182. Mason GF, Gruetter R, Rothman DL, Behar KL, Shulman RG, Novotny EJ. Simultaneous determination of the rates of the TCA cycle, glucose utilization, $\alpha$-ketoglutarate/glutamate exchange, and glutamine synthesis in human brain by NMR. J Cereb Blood Flow Metab 15:12-25, 1995.

183. Shen J, Petersen KF, Behar KL, Brown P, Nixon TW, Mason GF, et al. Determination of the rate of the glutamate/glutamine cycle in the human brain by in vivo 13C NMR. Proc Natl Acad Sci USA 96:8235-8240, 1999.

184. Boyce S, Wyatt A, Webb JK, O’Donnell R, Mason G, Rigby M, et al. Selective NMDA NR2B antagonists induce antinociception without motor dysfunction: correlation with restricted localisation of NR2B subunit in dorsal horn. Neuropharmacology 38:611623, 1999.

185. Chizh BA. Novel approaches to targeting glutamate receptors for the treatment of chronic pain: review article. Amino Acids 23: 169-176, 2002. 